\title{
Teaching digital skills to future teachers: a distance workshop experience
}

\author{
Floriana Falcinelli ${ }^{\mathrm{a}}$, Caterina Moscetti ${ }^{\mathrm{b}}$ \\ ${ }^{a}$ University of Perugia (Italy), floriana.falcinelli@unipg.it,0000-0003-2906-6356 \\ ${ }^{b}$ University of Perugia (Italy), caterina.moscetti@collaboratori.unipg.it
}

\begin{abstract}
In the school year 2020-2021, the Covid-19 pandemic imposed distance learning (in Italian, the DAD acronym is used). Therefore, the Degree Course in Primary Education Sciences of the University of Perugia has proposed an innovative programme for the training of future teachers by developing a distance learning laboratory focusing coding and computational thinking applied to teaching in kindergarten and primary school. During the educational technologies laboratory, held by Prof. Floriana Falcinelli, the students experimented coding both without computer (unplugged) and using the Scratch software. The programmed animations and video games were in direct connection with the Lifelong Kindergarten of the Massachusetts Institute of Technology (MIT) in Boston, where Scratch was created. The highly innovative aspects concerned both the proposed contents and the dimension of interaction and collaboration as entirely developed in online environments.
\end{abstract}

Keywords: coding; teacher training; computational thinking.

\section{Introduction}

The development of digital skills and their application in didactics is a focal topic discussed in Europe. It means that even the training of future teachers must re-evaluate didactics, so that the latter can be integrated with the use of new technologies. The direct application of Information and Communication Technologies (ICTs) is of utmost relevance within technology courses in education.

In the recent work of the European Commission entitled Survey of Schools: ICT in Education. Benchmarking Access, Use and Attitudes to Technology in Europe's Schools (2013, p. 89), it is stated: 'Although ICT training is included in initial teacher education in over half of all EU countries, implementation varies according to the higher education institutions providing the training, and a large portion of EU countries still have complete institutional autonomy in this area. In presence of the today's digital society and consequently teachers' need to integrate ICT into their daily teaching practice, countries might be wise to ensure that the ICT training is made a compulsory component of all initial teacher education programmes'.

Digital competence is considered by the European Commission to be one of the eight key competences for lifelong learning (CE, 2018). Therefore, future teachers must be trained, so that they are able, in turn, to teach in compliance with this principle. Within the European Framework for the Digital Competence of Educators (DigCompEdu) that was proposed in 2017, the digital competence of teachers is divided into six dimensions (https://ec.europa.eu/jrc/digcompedu) including the importance of Facilitating Learners' Digital Competence to promote students' digital competence (information and media literacy, communication, content creation, well-being, problem solving).

Therefore, it is necessary to teach teachers coding and computational thinking, also taking into account the importance of these topics in recent times, as shown in the document named 'Indicazioni nazionali e nuovi scenari' dated 2018 (National Guidelines by the Ministry for Education dated 2018). However, the aim was not so much to make students skilled in the use of the Scratch program as to understand its potential and transfer it into curricular teaching, in a trans-disciplinary perspective.

Moreover, teachers' technological training is stressed by the Piano Nazionale Scuola Digitale (PNSD) 2015 (National Digital School Plan dated 2015 - PNSD) which states: 'Teacher training must be centred on didactic innovation, taking 


\section{Teaching digital skills to future teachers: a distance workshop experience}

Falcinelli, F., Moscetti, C.

into account digital technologies as a support for the realization of new educational paradigms and operational planning of activities. We must move from the school of content transmission to that of learning [...]. The challenge of digitization is actually the challenge of innovation and this must answer the questions related to the need to widespread innovation within a complex organization such as a school'.

It is necessary to modify teachers' cultural attitudes, making them a part of a new vision of the future school, centred on new learning environments, contents, languages and new approaches to reality that ICTs provide. Within this perspective, teacher training should start within the context of basic-level university course classes and be transferred to their in-service training as well. In particular, some specific pedagogical and didactic topics should be included in the university curricula as well as in the regular computer courses.

The adopted methodology encompasses a particular level of relevance: it is, in fact, important for future teachers to experience new technologies, by exploring them actively and directly, working with them and comparing their discoveries, collaborating with others, while learning and understanding ICTs based on discovery and research and through integrating theory, workshop activities and practice.

The provision of a digital animator in each school, as required by the PNSD dated 2015, points precisely in this direction: supporting the teacher training by sharing work between peers and establishing a community of practices.

There are numerous educational experiences and a wide national and international debate both on the use of coding in primary and infant schools and the contexts in which Scratch is used in online environments that develop interaction and collaboration.

As regards the use of coding at school, the first important reflections at national level can be found in the documents that Indire has published both as research results (http://codingerobotica.indire.it/) and as a collection of relevant experiences on the use of coding in the classroom, aimed at teacher training (http://forum.indire.it/repository_cms/working/export/6604/\#/s istruzioni). In Italy, a large community of teachers approached coding through the training experiences initiated by the $M o o c$ CodeMOOC, Coding in your classroom, Now! (http://codemooc.org/). It was an open online course offered by the University of Urbino to help teachers introduce computational thinking in the classroom. In order to provide schools with a series of easily accessible tools to train students in the basic concepts of computer science, the Ministero dell'Istruzione (MIUR) has made available the Programma il futuro platform (https://programmailfuturo.it/) since 2014, which provides various types of activities that can be used online by students, both with the support of the teacher and autonomously.

On the use of Scratch in online environments, there are significant international experiences in which groups of teachers, educators and other interested people found communities in which, through the creation and sharing of projects, debates are issued and didactic paths are built that use coding to develop computational and creative thought. An interesting example is the Learning Creative Learning (LCL) community (http://lcl.media.mit.edu/) which, implemented and animated by the research group of Mitchel Resnick at Lifelong Kindergarten Massachusetts Institute of Technology (MIT) Boston, allows and encourages the collaborative participation of its members. They meet online to share reflections and develop projects, also availing themselves of Scratch, concerning the proposed topics.

Another interesting proposal from the aforementioned Boston laboratory is WeScratch (https://wescratch.media.mit. edu/), which in the reference site is described as follows: 'free online workshops for educators and everyone who wants to learn how to create projects with Scratch in an inclusive, collaborative, and playful social environment. People join from all over the world as we support multiple languages'. The pandemic has enhanced interesting experiments in which the didactic approach to coding as a tool for the development of computational and creative thinking has been applied in collaborative online environments aimed at young and very young people. For example, we can mention the experience of some Italian Coderdojo clubs (https://it.wikipedia.org/wiki/CoderDojo) that have organised a series of events called VirtualDojo (https://www.virtualdojo.it/it/ https://medium.com/unicorni/tutto-quello-che-serve-sapere-per-organizzare-un-virtual-dojo-8f3e5ec45a08), in which young people meet online and develop projects using Scratch, sharing paths and activities through various platforms, thanks to a constructive and non-directive approach to coding.

\section{Distance Educational Technology Workshop}

This workshop, carried out entirely remotely, had a total synchronous duration of 15 hours, divided into five meetings organised online in a workshop format. Each meeting included a theoretical introduction followed by a LabTime in peers in which students, in a collaborative online way, put into practice what was proposed in the first part of the day by sharing their projects in the Scratch online community.

The educational approach to coding was proposed creatively and constructively, also giving future teachers the tools to organise learning units that respond to the training needs and learning styles of today's pupils. At the end of the course, hundreds of projects created by the same students using Scratch's visual programming code were shared online.

The Laboratory of Technologies has enhanced this concept even further by linking it to the most innovative theories of the Lifelong Kindergarten of MIT in Boston, according to which the development of logical thinking goes hand in hand with the development of creative thinking (Resnick et al, 2017).

Both the didactic system of the Laboratory of Technologies and the organisational one in distance learning (DAD) were partly inspired by the innovative theories and experiments of the Lifelong Kindergarten of MIT in Boston. In fact, much attention was paid to the distance education experiences, carried out by the Lifelong Kindergarten of MIT in Boston through 


\section{Teaching digital skills to future teachers: a distance workshop experience}

Falcinelli, F., Moscetti, C.

the activities of the previously mentioned LCL community, and to Mitchel Resnick's reflections, in particular on topics concerning the creative approach to coding (https://mres.medium.com/ten-tips-for-cultivating-creativity-fe79e 7ebb83e).

The students experienced this relationship by connecting online with Carmelo Presicce, an Italian researcher who has been in Boston for years with Mitchel Resnick, the 'father' of Scratch. Presicce guided the students in engaging creative storytelling using Scratch, based on the Rodaris' fantastic combination and exploiting the software function 'surprise choice' of sprites (characters). Starting from the shared planning of a tale named 'Cinderella late for the space parade', the students created personal animated projects based on different stories and programming blocks. Presicce has started the discussion and opened questions on the importance of computational thinking combined with creative thinking, eliminating the prejudice that the computer scientist does not need creativity.

Furthermore, during the workshop, two in-depth seminars were held by Caterina Moscetti, an expert in the educational use of coding and internship coordinator at the university department. The first one was named 'Europe code week 2020 from code to teaching' and intended to propose an approach to programming as a cultural and educational element. The second one was named 'Learning Creative Learning' and concerned creative learning through Scratch.

The main topics of the seminars were robotics, coding and unplugged coding, computational thinking, programming interactive e-cards video games and designing a learning unit using coding. At the end of the course, hundreds of projects created by the students using Scratch's visual programming code were shared online. Computational thinking has been defined as the fourth basic skill together with reading, writing and counting, indispensable for everyone, because it is useful in everyday life (Wing, 2006). Future teachers must know how to create educational paths suitable for developing this kind of thinking in pupils.

The meetings were organised as follows.

First day: Introduction to coding, unplugged coding and computational thinking. Examples of computer-free coding-based teaching activities. Lab Time in peers: collaborative design of robotics and unplugged coding activities on a giant chessboard (including the construction of the necessary materials)

Second day: The 4Ps of Creative Learning: Design week. Europe Code week, coding-based curricular teaching practices. Lab Time in peers: 'Animate your name!' using Scratch

Third day: Project sharing realised by students and included in the Scratch community. The 4Ps of Creative Learning: Motivation (Passion) Week. Lab Time in peers: 'Using Scratch to create a project about yourself and your passions'

Fourth day: Speech by Carmelo Presicce, a researcher at Lifelong Kindergarten MIT Boston. The 4Ps of Creative Learning: the game intended as free and creative processing of the Scratch program scripts. Lab Time in peers

Fifth day: Project sharing realised by students and included in the Scratch Community. Lab Time in peers: 'Let's make a video game using Scratch' (https://scratch.mit.edu/projects/445151269)

This path is, therefore, suitable to the objectives set out in the Digital Competence of Educators (DigCompEdu) which emphasises how digital technologies can be used to improve and innovate training and education paths. In particular, the objectives concern the following areas: Area 3 on managing and orchestrating the use of digital tools in teaching and learning, Area 4 on digital tools and strategies to enhance assessment, Area 5 on the use of digital tools to empower learners and Area 6 on facilitating learners' digital competence. The biggest challenge was to try to achieve the objectives in the online/DAD environment and to demonstrate how it is possible to activate very collaborative and constructive education and training courses by exploiting the great potential of digital technologies and the Internet.

The specific objectives promoted by the workshop are as follows:

1.to use coding to develop digital competence and a correct approach to the development of students' computational thinking;

2.to provide an overview of unplugged coding activities;

3.to propose a teaching method as an alternative to the frontal lesson;

4.to provide an active and constructive learning perspective;

5.to encourage the design of creative programs;

6.to recognise the importance of error as a growth factor;

7.to enhance the sharing of teachers' training experiences and

8. to create a collaborative online training environment.

The design of the learning experience was based on the concepts of low flow, high ceiling and wide walls. The low floor is intended to provide beginners with simple basic instructions to get started and to allow them to work on increasingly sophisticated projects over time. The high ceiling and the wide walls are meant to design learning experiences where people could make different projects, working in different ways depending on their interests and styles (Resnick et alii, 2020). The progress of the projects carried out by the students shows this approach in practice: from the simplest animations of their name to the programming of a video game.

\section{Integration of different platforms and learning environments}

The workshop on coding and teaching responded to the inspiring principles of creative learning theorised by Mitchel Resnick of the Lifelong Kindergarten MIT in Boston. In this laboratory, Scratch was born (Resnick, 2009). The 4Ps of cre-

Research on Education and Media. Vol. 13, N. 2, Year 2021 - ISSN: 2037-0830 


\section{Teaching digital skills to future teachers: a distance workshop experience}

Falcinelli, F., Moscetti, $C$.

ative learning are Project, Play, Peer and Passion. This was achieved using an innovative experimental format described as follows. The students worked on projects, conceiving and realising them collaboratively online through coding. They did it with the spirit of the game, fun and challenge to achieve a goal. They were urged to follow their passions, creating and sharing projects on topics that stimulated their interest and motivation. The potential of the Internet was exploited to create a distance learning environment characterised by collaboration, sharing, peer learning, peer tutoring and active learning construction.

It was not an easy challenge because we were faced with a new way of organising a university laboratory. The element of the initial crisis, that is, the impossibility of being face-to-face, has been overcome and exploited by using three integrated platforms, each one for a specific purpose. An interesting and stimulating distance learning environment has been created as characterised by collaboration, peer learning and building learning activities. We designed it based on constructivist theories as well as distance learning experiences in which we were previously involved, experimental formats created before and during the 2020 lockdown, both in formal and non-formal learning environments. After analysing and evaluating experiences, we organised an integrated online environment including several platforms, which allowed an active involvement of students both in synchronous and asynchronous mode. The result is a model that has gone beyond the transmissive academic lesson and exploited the opportunities given by the condition that each student had a computer and an Internet connection constantly available. In the case of simultaneous presence of 80 students (the number of those attending the laboratory), it is not obvious to have a network that allows everyone to easily work using online applications and broadband.

We have integrated three platforms.

1. Unistudium. It is the official platform for the adoption of innovative e-learning methodologies of the University of Perugia based on Moodle and for support and in-depth materials. It was to be used asynchronously.

2. Teams. It was used for the online synchronous activities concerning the technology laboratory meetings and the peer activities, that is, exchange and collaboration between peers.

3. International Scratch Community. It is a space made available by the Lifelong Kindergarten MIT in Boston, where students shared their projects created through visual programming software. Students had access to a space created by us, called Gallery/Studio (https://scratch.mit.edu/studios/27668768/) in the community's language, dedicated to the technology laboratory where students uploaded their projects and had the opportunity to exploit the projects of their colleagues as well as those of the entire international community. The code of each project can be 'seen' and freely reused in personal projects, thanks to the remix function.

Students who have attended our laboratory are already engaged as trainee or substitute teachers in kindergarten or primary schools. These laboratory courses gave them the possibility of reusing even in online environments the skills acquired, by networking with their colleagues and thus bringing educational innovation to schools. A high number of students engaged as teachers in distance learning in primary schools have acquired the ability to organise online educational activities that involve pupils and make them active protagonists of their own collaborative and social construction of knowledge.

\section{Self-assessment of the development of computational practices}

In order to verify the achievement of the objectives defined in the previous paragraph, we set a number of research questions, listed below, which embraced the previously mentioned Digicomp areas in a transversal way.

1. Experimentation and iteration: To what extent have digital technologies and methodology used in an online collaborative environment (DAD) allowed to experiment with the creation of digital and educational products that differ from the examples seen?

2. Testing and debugging: To what extent have digital technologies and methodology used in an online collaborative environment (DAD) allowed to develop an aptitude for self-assessment, control and creative solution of procedural errors in one's work?

3. Reuse and remix: To what extent have digital technologies and methodology used in an online collaborative environment (DAD) allowed effective collaboration in the creation of educational digital products starting from sharing and exploiting collective intelligence in an open and meaningful way?

4. Abstraction and modularisation: How much have digital technologies and methodology used in an online collaborative environment (DAD) allowed to acquire and use specific skills in the proposed digital tools?

5. Didactic transferability: To what extent have digital technologies and the methodology used in an online collaborative environment (DAD) made it possible to acquire teaching skills that can be transferred to an educational context?

All students were offered to fill in an online self-assessment questionnaire on the development of computational practices. The questionnaire is based on an assessment tool designed by K. Brennan (https://scratched.gse.harvard.edu/ct/ files/Student_Assessment_Rubric.pdf). The percentage of answers was 100\% (79 responses). The items and possible responses were reshaped concerning the original questionnaire to adapt them to our self-assessment and the investigation needs. Open-ended questions were also introduced. The original division of the areas of exploration remained unchanged: experimentation and iteration, testing and debugging, reuse and remix, abstraction and modularisation. The field relating to the didactic transferability of the actions was added. 


\section{Teaching digital skills to future teachers: a distance workshop experience}

Falcinelli, F., Moscetti, $C$.

The objective of the questionnaire was to invite students to reflect on the experience and their deeper awareness of the Scratch resources. The self-assessment questionnaire showed that, after attending the laboratory, students declared an excellent propensity for experimentation and a good willingness to program debug and remodelling according to the needs of the project. The students' answers also demonstrate good use of the resources available through the remix, confirmed by the projects' remixing during the workshop. Students demonstrate that they know how to choose and use scripts appropriately, as well as sprites. In the section of the questionnaire devoted to this topic, a high index of didactic transferability emerges. The students state that coding is very useful for the development of creative and computational thinking and that Scratch is a useful teaching tool. An open question asked the students how they would use the software in teaching and, in general, an interdisciplinary use of coding was chosen. Another open-ended question investigated the main difficulties encountered in using the software and the strategies to solve them. Most responses show a willingness to work by trial and error and to adopt a constructive approach to sharing and collaborative problem solving. The procedures respond to the methodology proposed in the laboratory, highlighting how, even in online training environments, didactic approaches that envisage and promote collaboration and sharing are possible. The general satisfaction of the course was investigated through motivational indicators and didactic transferability of the topics covered. In both cases, the answer was positive.

\section{The self-assessment questionnaire: data in percentages}

The percentages of the answers given by students to the various items of the questionnaire, divided into areas, are shown below.

\begin{tabular}{|c|c|c|c|}
\hline EXPERIMENTATION AND ITERATION & Very much & Somewhat & Not much \\
\hline I got involved by experimenting with the tool & 67.1 & 31.6 & 1.3 \\
\hline I revised my Scratch project & 35.2 & 55.3 & 9.5 \\
\hline $\begin{array}{l}\text { I tried to do something new with respect to the Scratch program } \\
\text { as suggested by the teachers }\end{array}$ & 26.6 & 60.8 & 12.6 \\
\hline TEST AND DEBUGGING & Very much & Somewhat & Not much \\
\hline $\begin{array}{l}\text { I investigated the reasons for the problems in the Scratch project } \\
\text { I created }\end{array}$ & 49.4 & 46.8 & 3.8 \\
\hline I easily solved programming problems concerning Scratch & 6.3 & 77.2 & 16.5 \\
\hline I found different ways to solve problems & 24.1 & 63.3 & 12.6 \\
\hline I gave credit to a work of others that inspired me or that I remixed & 16.5 & 34.2 & 49.3 \\
\hline REUSE AND REMIXING & Very much & Somewhat & Not much \\
\hline I inserted a part of another project into mine & 5.1 & 26.5 & 68.4 \\
\hline I modified (remixed) an existing Scratch project to improve mine & 10.1 & 60.7 & 29.2 \\
\hline I gave credit to a work of others that inspired me or that I remixed & 16.5 & 34.2 & 49.3 \\
\hline ABSTRACTION AND MODULARISATION & Very much & Somewhat & Not much \\
\hline I chose sprites consistently for my project & 72.2 & 26.6 & 1.2 \\
\hline I chose the scripts in a functional way for the project & 62.0 & 38.0 & 0 \\
\hline I organised the scripts in a functional way for the project & 55.7 & 44.3 & 0 \\
\hline EDUCATIONAL TRANSFERABILITY & Very much & Somewhat & Not much \\
\hline $\begin{array}{l}\text { I believe that coding can be used for the development of compu- } \\
\text { tational thinking }\end{array}$ & 93.7 & 6.3 & 0 \\
\hline $\begin{array}{l}\text { I believe that coding can be used for the development of creative } \\
\text { thinking }\end{array}$ & 88.6 & 11.4 & 0 \\
\hline I believe that Scratch can be a useful teaching tool & 82.3 & 17.7 & 0 \\
\hline I think I use Scratch in my teaching & 58.2 & 39.2 & 2.6 \\
\hline
\end{tabular}

This question was added with an open space where students were invited to write their observations on how Scratch could be used in teaching. Here are some interesting answers. 


\section{Teaching digital skills to future teachers: a distance workshop experience}

Falcinelli, F., Moscetti, C.

'[It could be used] to stimulate computational and creative thinking, especially through teamwork that involves interaction and exchange of ideas. In this way the students will be more stimulated and motivated to carry on their activities, overcoming together the various problems that could (would) arise during the project'.

'I hope so, that is, there are possibilities to use Scratch and, above all, to make the students use it. It is indeed interdisciplinary and inclusive. I think it can allow everyone to learn while having fun (hard fun)'.

'It is possible to apply Scratch to all disciplines, from mathematics to the Italian language, as it allows students to process interactive stories, games, animations, art, and music'.

'I think I will use Scratch across various disciplines, to create interactive projects in which students can be active protagonists, not just users, of learning. But above all, I will use it to develop computational thinking in them, a competence that the citizens of tomorrow must necessarily have'.

'Scratch could be both the starting point of a teaching unit (in Italian UDA) and an additional activity. It would be certainly useful to stimulate the students' desire to get involved and to experience the frustration and at the same time the gratification of producing something by themselves'.

' [I will use Scratch] to create personalized activities where students can use both elements of their personal life and other casual and imaginative ones. Students learn to use logic while they play programming'.

'Scratch can be used in different ways, especially in an interdisciplinary one, for example by making the students study a given historical figure by animating it'.

'Technology and Scratch can be used in any discipline to make work more engaging'.

'It would be useful to use Scratch as a creative activity that can check the contents in an alternative way. Storytelling is an example of it'.

'Scratch can be useful to make dynamic a narrative text already given, to create work materials to be shared, etc.' .

'[Scratch can be used] to create stories or games with children'.

'[Scratch can be used] by proposing unplugged coding activities in kindergarten on numbers or rhymes, or by proposing plugged activities in childhood for all the disciplines that make it possible'.

'I'd use Scratch mostly for story creation'.

\section{Discussion}

The laboratory experience, even if carried out in DAD, has allowed students to achieve significant results as far as the knowledge of coding and the possible use of Scratch in the school environment is concerned.

The laboratory stimulated curiosity about the tool and its possible use in the didactic field, even if the fact of not having been able to experience this activity in the direct internship under the supervision of the two teachers of the laboratory made the possible didactic applicability of the tool less clear. However, the data presented above show that an experimentation has been initiated that will make tutorls exchange their ideas at school during the internship. It has to be stressed that students realised that Scratch is an interdisciplinary resource for inclusive teaching and to motivate pupils to work cooperatively. This approach enhances the comparison between peers and is an important tool for enhancing imagination and creative thinking.

This was possible and favoured, thanks to the integrated use of online platforms that have stimulated and enhanced remote exchange even with researchers from Boston. The DAD was, therefore, a resource that allowed a more social and shared approach of the Scratch tool and, for this reason, more creative. The DAD also allowed the group of students to share the difficulties in making the various products and to help each other.

\section{Conclusions}

The workshop herein underlines the need to create goals aimed at allowing future teachers to acquire a deep understanding of coding and have the possibility to actively utilise Scratch to make teaching more efficient and help students to become more aware of their technological experience. Undoubtedly, the development of any digital competence in the future teachers must walk hand in hand with adequate pedagogical training since 'technology alone does not facilitate new forms of learning' (OECD, 2016). Therefore, the need for training on how to teach the use of new technologies during the didactic practice is stressed. The Recommendations of the European Parliament and the Council (2018) clearly state that competence is a concept that involves notions and skills not from a summative perspective, but in a more synergetic context (TPCK, 2008). In the domestic context, the National Digital School Plan (PNSD - MIUR, 2015) underlines the close relationship between technological innovation in schools and teacher training on the use of ICTs and their understanding from a pedagogical perspective. For this reason, redesigning teacher training is of utmost importance to foster a harmonious and integral development of pedagogical-didactic-methodological, psychosocial assessment, didactic innovation and experimentation skills.

The achievement of the objectives set by the laboratory was self-assessed on the basis of the projects shared by the Scratch community and the oral interviews with the students. In our opinion, the biggest challenge, that is, to develop 


\section{Teaching digital skills to future teachers: a distance workshop experience}

Falcinelli, F., Moscetti, C.

collaboration and constructive learning in DAD, was met. Students, indeed, reached high values as far as the perception of a collaborative climate with the members of the group was concerned. In a similar way, they also proved to have acquired teaching competence with respect to the type of approach proposed.

It is, therefore, clear that the methodological approach to the activities proposed in DAD makes the difference with respect to the results obtained. In a pandemic period when the DAD was strongly criticised because of the passivating effects it can have had on students, we have experienced that it is possible to develop competence, interest and motivation if online educational activities create a collaborative and active environment by exploiting the potential of the Internet. In an interesting article, Resnick states that: 'Some schools implemented remote-learning routines focused on delivery of instruction based on the traditional curriculum; in those schools, many students felt increasingly isolated and disillusioned. Other schools focused more on social-emotional aspects of learning, emphasizing the importance of supporting and understanding one another; in those schools, students felt a stronger sense of connection, community, empathy, and engagement' (https://medium.com/open-learning/perspectives-from-the-pandemic-a-renewed-appreciation-for-connection-and-community-5dd5c488e8fc).

The adoption of a laboratory methodology that facilitates the discovery approach and cooperative teamwork is very important. The experience we have conducted has made us understand that even at a distance, this is possible if various platforms and interconnected resources are integrated. Distance education was, therefore, not an obstacle; on the contrary, it enhanced the online group experimentation of the tool and sharing in the Scratch community in which the students participated, by expanding their vision and didactic perspective.

\section{References}

AACTE Committee on Innovation and Technology (2008). Handbook of Technological Pedagogical Content Knowledge (TPCK) for Educators. New York: Routledge.

Brennan, K., \& Resnick, M. (2012). New Frameworks for Studying and Assessing the Development of Computational Thinking. Proceedings of the 2012 annual meeting of the American Educational Research Association. Vancouver.

Brennan, K., Balch, C., \& Chung, M. (s.d.). Creative Computing. Retrieved February 23, 2018, from https://goo.gl/ MwHTnH

European Commission (2013). Survey of Schools: ICT in Education. Benchmarking Access, Use and Attitudes to Technology in Europe's Schools. doi:10.2759/94499

Gabaree, L., Rodeghiero, C., Presicce, C., Rusk, N. \& Jain, R. (2020). Designing creative and connected online learning experiences. Information and Learning Sciences, CXXI(7/8), 655-663.

Legge 13 luglio 2015, n. 107. Riforma del sistema nazionale di istruzione e formazione e delega per il riordino delle disposizioni legislative vigenti. Retrieved February 23, 2018 from https://goo.gl/ZAi8uQ

Ministero dell'Istruzione, dell'Università e della Ricerca (MIUR) (2015). Piano Nazionale Scuola Digitale. Retrieved February 23, 2018 from https://goo.gl/NA2Vsq

Organization for Economic Co-operation and Development (OECD) (2016). Working Party on Measurement and Analysis of the Digital Economy. Skills for a digital world. Retrieved January 26, 2018 from https://goo.gl/PqjPdp

Presicce, C., Jain, R., Rodeghiero, C., Gabaree, L.E. \& Rusk, N. (2020). WeScratch: an inclusive, playful and collaborative approach to creative learning online. Information and Learning Sciences, CXXI(7/8), 695-704.

Redecker, C. (2017). European Framework for the Digital Competence of Educators: DigCompEdu. In Punie Y. (ed.). EUR 28775 EN. Luxembourg: Publications Office of the European Union. doi:10.2760/159770

Scratch. Retrieved February 23, 2018 from https://goo.gl/udrCpH

Wing, J. M. (2006). Computational Thinking. Communications of the ACM, ILIX(3), 33-35.

Resnick, M. (2017). Lifelong Kindergarten: Cultivating Creativity through Projects, Passion, Peers, and Play. Cambridge (MA), MIT Press.

Resnick, M., Maloney, J., Monroy-Hernández, A., Rusk, N., Eastmond, E., Brennan, K., Millner, A., Rosenbaum, E., Silver, J., Silverman, B., \& Kafai, Y. (2009). Scratch: Programming for all. Communications of the ACM, LII(11), 60-67.

Resnick, M., \& Rusk, N. (2020). Coding at a Crossroads. Communications of the ACM, LXIII(11), 120-127 (Italian version). 